\title{
Normothermic ex vivo lung perfusion outperforms conventional cold preservation in a deceased rat lung
}

\author{
Weimin Wang ${ }^{1 \#}$, Jie Qian ${ }^{2 \#}$, Minfang Zhu' ${ }^{3}$, Yinghua Wang ${ }^{3}$, Yan Pan ${ }^{4}$ \\ ${ }^{1}$ Department of Pulmonary Medicine, Shanghai Chest Hospital, Shanghai Jiao Tong University, Shanghai, China; ${ }^{2}$ Department of Emergency \\ Medicine, Shanghai Chest Hospital, Shanghai Jiao Tong University, Shanghai, China; ${ }^{3}$ Department of Critical Care Medicine, Shanghai Chest \\ Hospital, Shanghai Jiao Tong University, Shanghai, China; ${ }^{4}$ Department of Pharmacology, Shanghai Chest Hospital, Shanghai Jiao Tong University, \\ Shanghai, China \\ Contributions: (I) Conception and design: W Wang, J Qian, Y Pan; (II) Administrative support: Y Pan; (III) Provision of study materials or patients: \\ J Qian, M Zhu, Y Pan; (IV) Collection and assembly of data: W Wang, Y Wang, Y Pan; (V) Data analysis and interpretation: W Wang, J Qian, Y \\ Wang, Y Pan; (VI) Manuscript writing: All authors; (VII) Final approval of manuscript: All authors. \\ \#These authors contributed equally to this work. \\ Correspondence to: Dr. Yan Pan. Department of Pharmacology, Shanghai Chest Hospital, Shanghai Jiao Tong University, \#241 West Huaihai Rd., \\ Shanghai 200030, China. Email: tt37py@qq.com; Dr. Yinghua Wang. Department of Critical Care Medicine, Shanghai Chest Hospital, Shanghai \\ Jiao Tong University, \#241 West Huaihai Rd., Shanghai 200030, China. Email: pen1019@hotmail.com.
}

Background: Utilization rate of donor lungs in China is constrained by the inefficiency of conventional cold preservation (COLD) in lung transplantation. We assessed the performance of normothermic ex vivo lung perfusion (EVLP) in lung donors following cardiac death (DCD) with fresh EVLP perfusate.

Methods: A total of 24 adult Sprague-Dawley (SD) rats were randomized into three groups (EVLP, COLD, and control groups) with 8 rats each. Fresh EVLP perfusate was prepared for lung perfusion. The $\mathrm{pH}$, electrolyte concentration, perfusate penetration pressure during irrigation, physiological function, integrity of barrier function, pathological changes, and expressions of inflammation-related cytokines of donor lungs were examined.

Results: The $\mathrm{pH}$, electrolyte concentration, osmotic pressure of the perfusate were kept stable for 4 hours after EVLP was administered. Pulmonary arterial pressure (PAP), pulmonary venous pressure (PVP), pulmonary venous oxygenation index $\left(\mathrm{PaO}_{2} / \mathrm{FiO}_{2}\right)$, and end carbon dioxide partial pressure $\left(\mathrm{PCO}_{2}\right)$ in the EVLP group were all within acceptable limits. After 4 hours, the oxygenation index was significantly higher in the EVLP group compared with that of the COLD group $(\mathrm{P}=0.0032)$. The EVLP group had a decreased wet/dry weight ratio $(\mathrm{P}=0.0155)$ and Evans blue dye content $(\mathrm{P}=0.0075)$ compared to that of the COLD group. Pathological examination showed more obvious lung damage in the COLD group than in the EVLP group. However, there was no difference in protein expression of high mobility group box 1 (HMGB1) and toll-like receptor 4 (TLR4) between the EVLP group and the COLD group.

Conclusions: Fresh lung perfusate could be used for EVLP to protect and repair donor lungs. Normothermic EVLP performed better than conventional cold preservation. EVLP might be powerful for lung quality maintenance and may have potential for anti-inflammation.

Keywords: Ex vivo lung perfusion (EVLP); cold storage; lung transplantation; high mobility group box 1; toll-like receptor 4

Submitted Dec 22, 2021. Accepted for publication Jan 21, 2022.

doi: $10.21037 / \mathrm{atm}-22-42$

View this article at: https://dx.doi.org/10.21037/atm-22-42 


\section{Introduction}

Although lung donation from deceased donors continues to increase, successful lung donation following cardiac death (DCD) is still rare and accounted for less than $1 \%$ of all deceased donor lungs in 2005 (1). A recent study showed that, in China, donor lungs following cardiac death still had a low utilization rate due to the inefficiency of conventional cold preservation in lung transplantation (2). Moreover, marginal lungs were often wasted due to inappropriate management or preparation. Ex vivo lung perfusion (EVLP) is a promising technique to improve effect of marginal lungs preparation for transplantation (3). With normothermic EVLP, physiologic conditions of the donor lungs are well-maintained during perfusion (4). Previous studies, which were mainly performed in western countries, have shown that injured or normal donor lungs could sustain physiological functions after perfusion in the normothermic EVLP system $(5,6)$.

The Steen solution is a commonly used perfusate for EVLP. It is a low potassium, dextran and albumincontaining solution which contains a similar ion concentration as extracellular fluid (7). The Steen solution can remove excess moisture from the lung interstitial and alveoli and can protect the integrity of the alveolar capillary membrane with physiological osmotic pressure (8-10). However, the cost and availability of the Steen solution limits the availability of the EVLP technique in China.

In our research, we prepared fresh lung perfusate which could meet the needs of EVLP and protect DCD lungs. Our study will provide a new evaluation of the novel EVLP technique for future potential clinical application across China. We present the following article in accordance with the ARRIVE reporting checklist (available at https://atm. amegroups.com/article/view/10.21037/atm-22-42/rc).

\section{Methods}

\section{Animals}

All Sprague-Dawley (SD) rats, male individuals >9 weeks, were purchased from the experimental animal center of Shanghai Jiao Tong University School of Medicine. Animals were intraperitoneally anesthetized with $10 \%$ chloral hydrate, shaved, and sterilized. We cut the skin along the anterior midline of the neck, separated the subcutaneous tissue muscle layer, tracheotomized the animals with a venous retention needle as the tracheal catheter, and connected the ventilator for ventilation. The ventilation parameters were as follows: air volume $5 \mathrm{~mL} / \mathrm{kg}$; positive end-expiratory pressure (PEEP) $2 \mathrm{cmH}_{2} \mathrm{O}$; respiratory rate 60 times/min; $\mathrm{FiO}_{2}$ 0.21; and tidal volume $7 \mathrm{~mL} \cdot \mathrm{kg}^{-1}$. The rats were injected with heparin $600 \mathrm{U}$ into the inferior vena cava. The abdominal cavity was opened. Donor rats were euthanized by exsanguination from the inferior vena cava and life support was stopped. A total of 24 adult SD rats with body weight of 350-450 grams were randomized into the following three groups:

(I) The DCD + EVLP group (EVLP group): the lungs were kept in situ for 1 hour and then flushed with $15 \mathrm{~mL}$ of $4{ }^{\circ} \mathrm{C}$ extracellular electrolyte solution Perfadex (XVIVO Perfusion AB), followed by EVLP with the self-developed lung perfusion for 4 hours at $37^{\circ} \mathrm{C}$;

(II) The DCD + COLD group (COLD group): the lungs were kept in situ for 1 hour and kept semiinflated and preserved in cold $\left(4^{\circ} \mathrm{C}\right)$ storage for 3 hours, followed by EVLP with the self-developed lung perfusion for 1 hour at $37^{\circ} \mathrm{C}$;

(III) The control group (control group): rats were shamoperated.

The experiment was approved by the ethics committee of Shanghai Chest Hospital (No. KS2058), in compliance with institutional guidelines for the care and use of animals. A protocol was prepared before the study without registration

\section{Surgical procedure}

We fixed the animals and cut the diaphragm and both sides of the chest wall along the "U type" of the inner chest artery. We turned the front chest wall upward to expose the mediastinum and chest cavity. The pulmonary artery and the root of the aorta were detached. The right ventricular surface was cut with a $2-\mathrm{mm}$ incision, and the pulmonary artery perfusion tube was inserted, ligated, and fixed. The apex was cut, and the mitral valve was expanded with tweezers. Pulmonary artery perfusion $(20 \mathrm{~mL}$ Perfadex + $3 \mu \mathrm{g}$ alprostadil) was performed at a speed of $2 \mathrm{~mL} / \mathrm{min}$. The left atrial cannula was inserted into the left atrium from the left ventricle through the mitral valve, and the cannula was fixed. A volume of $3 \mathrm{~mL}$ of perfadex was used for retro-perfusion. The heart and lung were harvested and fixed. Figure 1 shows the EVLP set-up and the self-designed 
A

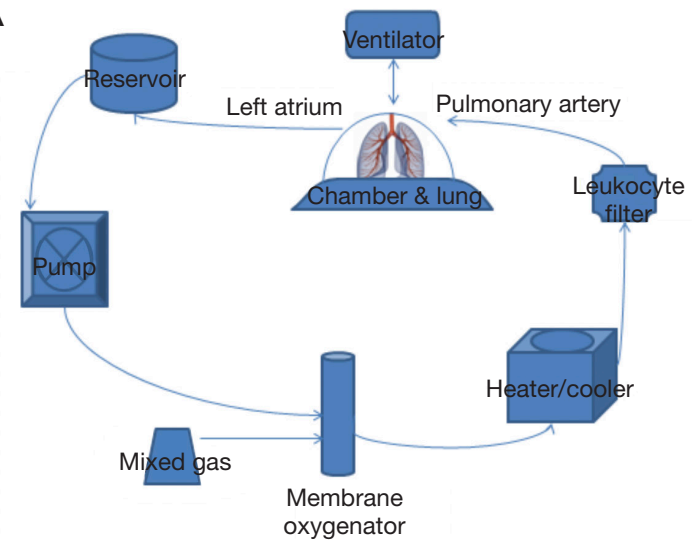

B

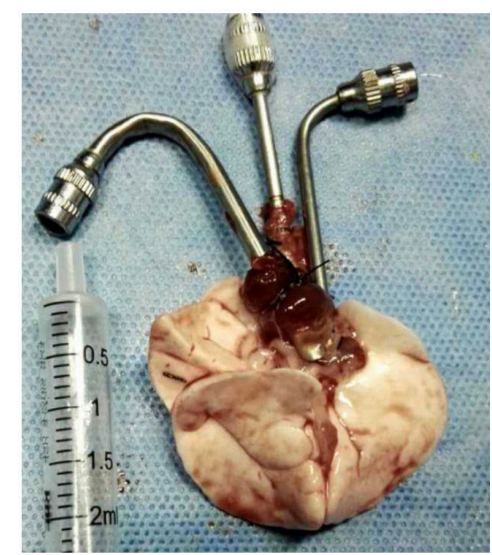

Figure 1 EVLP procedure and cannulas. (A) Schematic diagram of EVLP; (B) self-designed pulmonary artery cannula and pulmonary vein cannula. EVLP, ex vivo lung perfusion.

pulmonary artery and pulmonary vein cannulas.

\section{Lung perfusate preparation}

The lung perfusate applied in this study was prepared by us according to the Steen solution formula. First, dextran-20 $(50 \mathrm{~g})$ was heated and dissolved in distilled water. Second, separately from the first solution, distilled water was prepared with dissolved sodium chloride $(8 \mathrm{~g})$, potassium chloride $(0.4 \mathrm{~g})$, magnesium sulfate $(0.098 \mathrm{~g})$, disodium hydrogen phosphate anhydrous $(0.046 \mathrm{~g})$, potassium dihydrogen phosphate $(0.063 \mathrm{~g})$, calcium chloride $(0.06 \mathrm{~g})$ and glucose $(0.9 \mathrm{~g})$. These two solutions were mixed, albumin $50 \mathrm{~g}$ added and the volume was adjusted to $1,000 \mathrm{~mL}$ with distilled water. The combined liquid was filtered with a sterile filter and stored at $4{ }^{\circ} \mathrm{C}$. Methylprednisolone $(40 \mathrm{mg})$, cefazolin $(100 \mathrm{mg})$, and sodium heparin $(1,000 \mathrm{U})$ were added to the combined liquid solution per $100 \mathrm{~mL}$ volumes immediately before it was used.

\section{EVLP protocol}

The pipeline was filled with $60 \mathrm{~mL}$ of lung perfusion solution initially and subsequently supplemented with the solution at a speed of $10 \mathrm{~mL} / \mathrm{h}$. Continuous perfusion was maintained for 4 hours with the initial pulmonary artery flow (PAF) computed as: $\mathrm{PAF}=20 \% \times 6 \mathrm{~mL} / \mathrm{min} / \mathrm{g} \times$ predicted lung weight $(\mathrm{PLW})$, where PLW $=0.0053 \times$ body mass $-0.48 \mathrm{~g}$.

The perfusion lasted for about half an hour, and PAF was gradually increased to $100 \%$. The perfusion temperature was maintained at $37{ }^{\circ} \mathrm{C}$. The ventilation strategy in the EVLP bypass was as follows: air frequency 50 times/min; PEEP $2 \mathrm{cmH}_{2} \mathrm{O}$; the initial tidal volume 5 and $7 \mathrm{~mL} / \mathrm{kg}$ after $10 \mathrm{~min}$.

\section{Measurement}

Lungs in the EVLP group were harvested and flushed with $4{ }^{\circ} \mathrm{C}$ perfusion liquid and immediately underwent EVLP (4 hours EVLP at $37^{\circ} \mathrm{C}$ ). Lung physiology was measured every hour during the reperfusion. The blood gas was withdrawn after 5 minutes of $100 \% \mathrm{O}_{2}$ ventilation. The physiological functional parameters including pulmonary artery pressure (PAP), pulmonary venous pressure (PVP), oxygenation index $\left(\mathrm{PaO}_{2} / \mathrm{FiO}_{2}\right.$, the results of blood gas from the pulmonary vein), and peak airway pressure (PAWP) were measured at 1 hour intervals during the experiment.

The right lower lobe from each animal was weighed immediately after collection and then placed into a $60{ }^{\circ} \mathrm{C}$ oven to dry. After 72 hours, the tissue was weighed to determine the wet-to-dry lung weight ratio.

The Evans blue concentration was measured for the detection of vascular permeability. Evans blue $1 \mathrm{~mL}(1 \%)$ was perfused through the pulmonary artery, and rinsed with perfadex. Then, $100 \mathrm{mg}$ of lung tissue was taken and cut into small pieces. Formamide $(2 \mathrm{~mL} / 100 \mathrm{mg})$ was added, and the tissue was put into the water bath $\left(50{ }^{\circ} \mathrm{C}\right)$ for 24 hours. After that, the tissue was centrifuged, and the supernatant was collected. Evans blue dye was measured in a spectrophotometer at $620 \mathrm{~nm}$. 
Table 1 Ion concentration and osmotic pressure of lung perfusates in each hour

\begin{tabular}{lcccccc}
\hline Time $(\mathrm{hr})$ & $\mathrm{pH}$ & $\mathrm{Na}^{+}(\mathrm{mmol} / \mathrm{L})$ & $\mathrm{K}^{+}(\mathrm{mmol} / \mathrm{L})$ & $\mathrm{Cl}^{-}(\mathrm{mmol} / \mathrm{L})$ & $\mathrm{Ca}^{2+}(\mathrm{mmol} / \mathrm{L})$ & Osmotic pressure $(\mathrm{mOsm} / \mathrm{L})$ \\
\hline 1 & $6.86 \pm 0.28$ & $146.25 \pm 4.98$ & $4.76 \pm 0.17$ & $113.13 \pm 4.12$ & $0.62 \pm 0.03$ & $292.89 \pm 8.28$ \\
2 & $6.87 \pm 0.34$ & $151.75 \pm 5.39$ & $4.55 \pm 0.28$ & $114.50 \pm 3.78$ & $0.65 \pm 0.04$ & $303.68 \pm 8.48$ \\
3 & $6.79 \pm 0.21$ & $151.88 \pm 3.31$ & $4.75 \pm 0.33$ & $109.88 \pm 4.29$ & $0.61 \pm 0.05$ & $294.26 \pm 7.20$ \\
4 & $6.72 \pm 0.20$ & $148.88 \pm 4.22$ & $4.63 \pm 0.32$ & $112.50 \pm 4.09$ & $0.63 \pm 0.05$ & $296.55 \pm 9.46$ \\
$\mathrm{~F}$ & 0.558 & 2.776 & 1.030 & 1.969 & 1.646 & 2.614 \\
$\mathrm{P}$ & 0.647 & 0.060 & 0.394 & 0.141 & 0.201 & 0.071 \\
\hline
\end{tabular}

Pathological analysis was performed on the left upper lung tissue. Lung sections were sliced from paraffin embedded lungs. Hematoxylin-eosin (H\&E) staining was routinely performed.

Immunohistochemical staining of toll-like receptor 4 (TLR4) and high mobility group box 1 protein-1 (HMGB1) was performed on lung tissue. Consecutive slides were incubated with $3 \%$ hydrogen peroxide at room temperature for 10 minutes to block endogenous peroxidase after dewaxing and rehydrating. Then, the samples were incubated overnight at $4{ }^{\circ} \mathrm{C}$ with the anti-TLR4 antibody and the anti-HMGB1 antibody (Abcam, Cambridge, Massachusetts, USA).

After rewarming at room temperature for $45 \mathrm{~min}$, the secondary antibody (Max-Vision ${ }^{\mathrm{TM}}$ kit; MaxVision BioSciences, Washington, USA) that was marked with horseradish peroxidase-labeled polymer (HRP) was added and incubated at $37{ }^{\circ} \mathrm{C}$ for 30 minutes. 3,3'-diaminobenzidine was used to develop the color. Mayer's hematoxylin was used for counterstaining.

Western blot analysis was performed to detect the protein expression of TLR4 and HMGB1 in the lung tissue. The proteins were extracted using the RadioImmunoprecipitation Assay (RIPA) buffer, and the protein concentration was determined using the Bicinchoninic Acid (BCA) method. Antibodies to TLR4 (Novus, Cjzu0309, 1:1,000) and HMGB1 (Abcam, Gr3187607-5, 1:1,000) were used.

\section{Statistical analysis}

Statistical analysis was performed with GraphPad Prism 7 (GraphPad Software Inc., La Jolla, CA, USA). All data were expressed as mean \pm SD or median (interquartile). The Mann-Whitney test was used to compare the physiological parameters, and a one-way analysis of variance (ANOVA) analysis was used for the comparison among groups. The Pearson correlation analysis was performed to identify the strength of relationships. A $\mathrm{P}$ value less than 0.05 was considered to be statistically significant.

\section{Results}

\section{Changes of ion concentration and osmotic pressure of lung perfusates}

The $\mathrm{pH}$ and main ion concentration were determined using a blood gas analyzer. See Table 1 for details. There was no significant change in the fluid $\mathrm{pH}$ value, ion concentration, and osmotic pressure during the perfusion $(\mathrm{P}>0.05 ; \mathrm{n}=8)$.

\section{Lung functional assessment during 4 bours of EVLP}

In the process of 4 hours of EVLP perfusion, the levels of PAP, PVP, oxygenation index, and PAWP in the EVLP group were all within acceptable limits. In the fourth hour, the oxygenation index remained at $340.37 \pm 31.16 \mathrm{mmHg}$ (Figure 2).

\section{Comparisons of lung physiology between the EVLP and the COLD groups}

After 4 hours, the oxygenation index was significantly higher in the EVLP group compared with that of the COLD group $(\mathrm{P}=0.0032)$. However, the PAWP was significantly lower in the EVLP group compared with that of the COLD group $(\mathrm{P}=0.0233)$ (Figure 3).

\section{Comparisons of wet/dry weight ratio and Evans blue dye content among the three groups}

At the fourth hour, the wet/dry weight ratio in the EVLP 

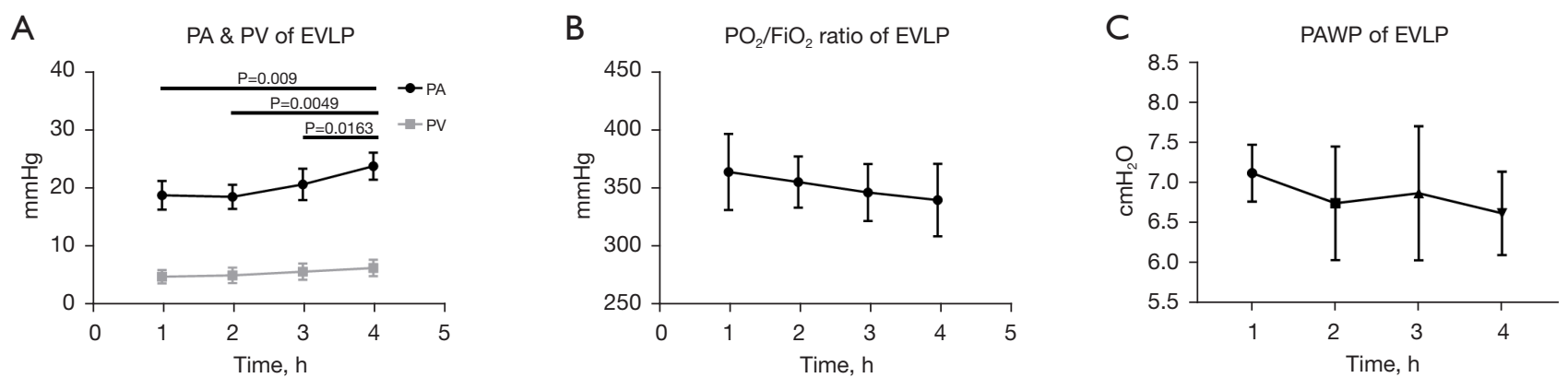

Figure 2 Lung functional assessment during 4 hours of EVLP perfusion. (A) Mean pulmonary artery pressure and pulmonary vein pressure; (B) oxygenation as represented by $\mathrm{PaO}_{2} / \mathrm{FiO}_{2}$; (C) peak airway pressure. PA, pulmonary artery; PV, pulmonary venous; PAWP, peak airway pressure; EVLP, ex vivo lung perfusion; $\mathrm{PaO}_{2} / \mathrm{FiO}_{2}$, the ratio of partial pressure of oxygen to fraction of inspired oxygen.
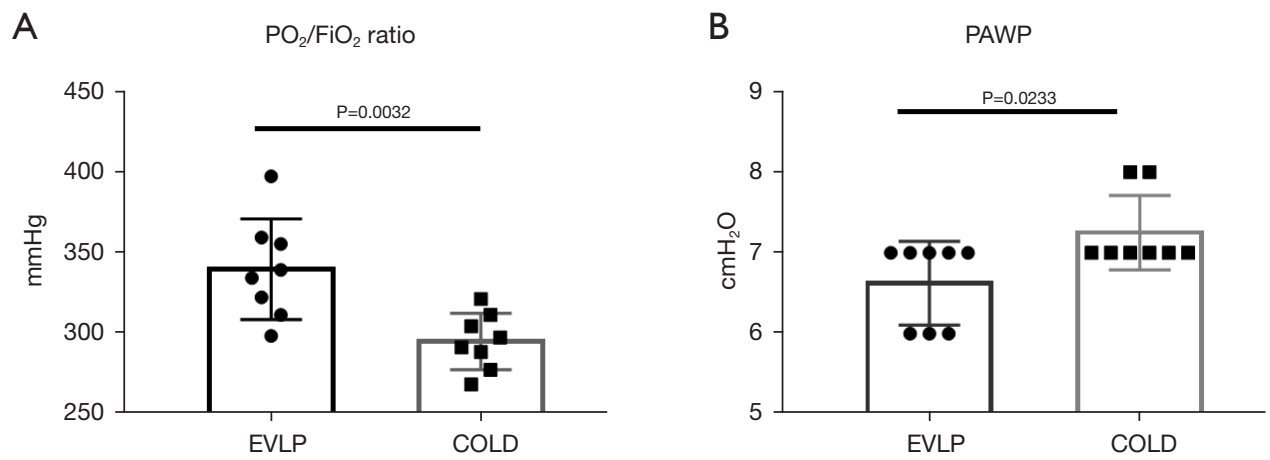

Figure 3 Comparisons of lung functional assessment between the EVLP and the COLD groups. (A) Oxygenation as represented by $\mathrm{PaO}_{2} / \mathrm{FiO}_{2}$; (B) peak airway pressure. EVLP, ex vivo lung perfusion; COLD, conventional cold preservation; PAWP, peak airway pressure; $\mathrm{PaO}_{2} / \mathrm{FiO}_{2}$, the ratio of partial pressure of oxygen to fraction of inspired oxygen.

and the COLD group was both significantly greater than that of the control group (COLD vs. control: $\mathrm{P}<0.0001$, EVLP vs. control: $\mathrm{P}=0.0003)$. However, the EVLP group had a decreased wet/dry weight ratio compared to that of the COLD group $(\mathrm{P}=0.0155)$. Similarly, the Evans blue dye content was significantly lower in the EVLP group than in the COLD group $(\mathrm{P}=0.0075)$ (Figure 4).

\section{Comparison of protein expression of TLR4 and HMGB1 among the three groups}

The protein expressions of TLR4 and HMGB1 were both significantly upregulated in the EVLP and the COLD groups compared with those of the control group. However, TLR4 and HMGB1 expressions were not significantly different between the EVLP and the COLD groups. In addition, TLR4 expression level positively correlated with HMGB1 level $\left(\mathrm{R}^{2}=0.5003 ; \mathrm{P}=0.0001\right)$ (Figure 5).

\section{Pathological and histochemical changes}

Pathological examination by H\&E staining showed complete alveoli structure without alveolar disruption, hemorrhage, edema, and severe inflammatory cell infiltration in the control group. However, increased inflammatory cell infiltration, pulmonary interstitial edema, partial alveolar fusion, and wall collapse were noticed in the EVLP and COLD groups, which seen to a greater extent in the latter. Similarly, increased upregulated TLR4 and HMGB1 expression in the lung tissue was seen in the EVLP and COLD groups. Immunohistochemical staining showed that TLR4 was expressed in the cell membrane and HMGB1 was expressed in the alveoli (Figure 6).

\section{Discussion}

We established a rat model of EVLP with self-made 

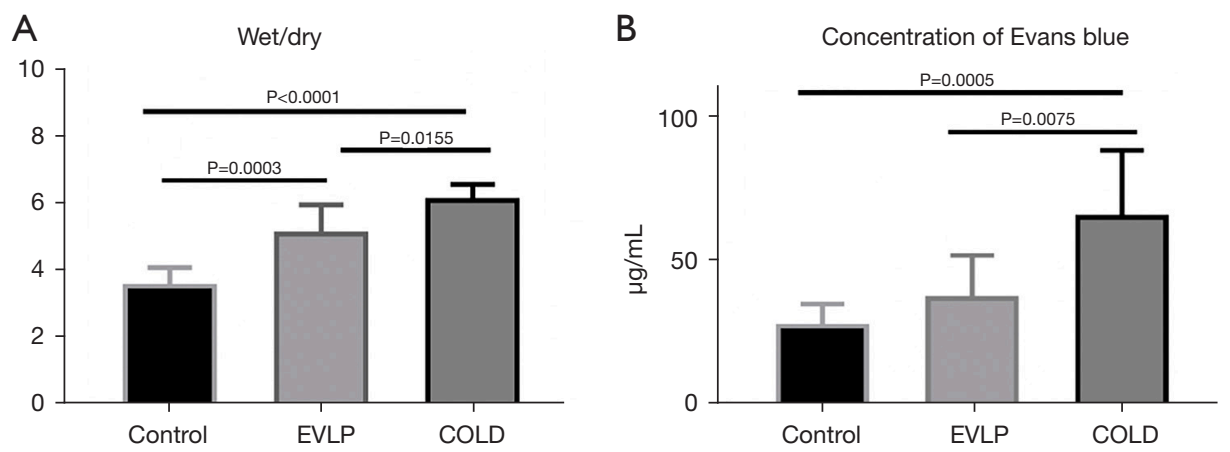

Figure 4 Comparisons of wet/dry weight ratio and Evans blue dye content among the three groups. (A) Wet-to-dry weight ratio; (B) concentration of Evans blue dye. EVLP, ex vivo lung perfusion; COLD, conventional cold preservation.

A

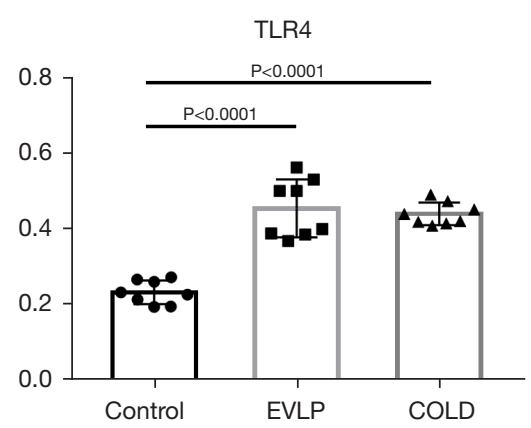

C

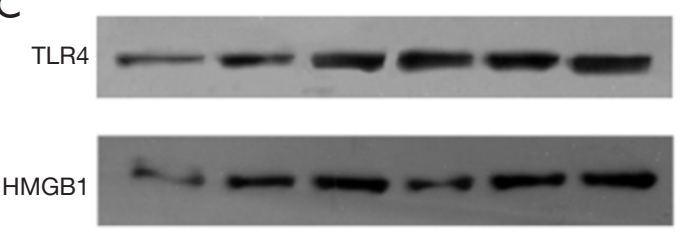

$\beta$-actin

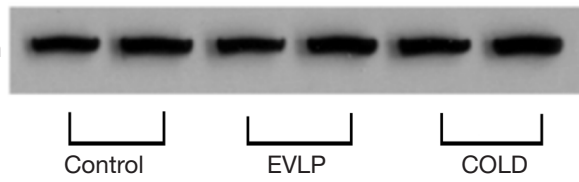

B

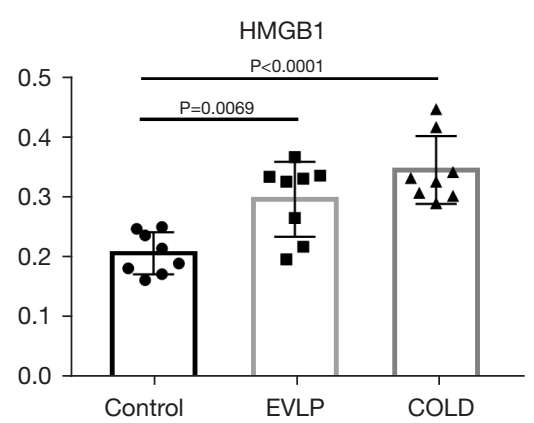

D

Correlation of HMGB1 and TLR4

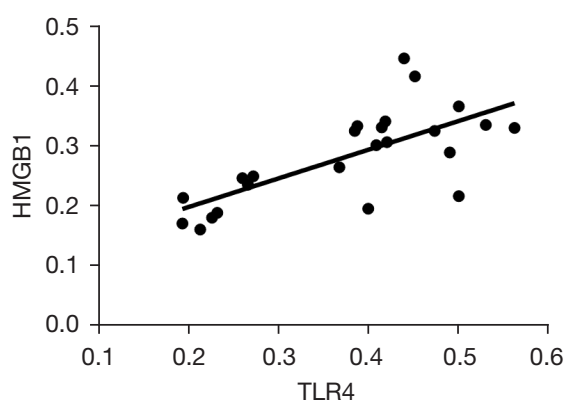

Figure 5 Western-blot analysis and correlation of TLR4 and HMGB1 proteins. (A-C) TLR4 and HMGB1expression; (D) correlation between HMGB1 and TLR4. EVLP, ex vivo lung perfusion; COLD, conventional cold preservation; TLR4, toll-like receptor 4; HMGB1, high mobility group box 1 .

cannulas, fresh perfusate, and a well-designed procedure. Our findings showed that normothermic EVLP for 4 hours outperformed conventional cold preservation in terms of physiological function, extent of lung edema, and integrity of barrier function, as shown by acceptable levels of PAP, PVP, oxygenation index, and PAWP, decreased wet/dry weight ratio, and Evans blue dye content.
To confirm whether lung function was adequate for transplantation, we measured a combination of physiological parameters that addressed gas exchange (oxygenation index $\mathrm{PaO}_{2} / \mathrm{FiO}_{2}$ and $\mathrm{PAWP}$ ) and pulmonary circulation (PAP and PVP). Based on previous reports, if the $\mathrm{PaO}_{2} / \mathrm{FiO}_{2}$ value was greater than $350 \mathrm{mmHg}$ (of, in some studies, ranged from 300 to $400 \mathrm{mmHg}$ ), the lung was determined 

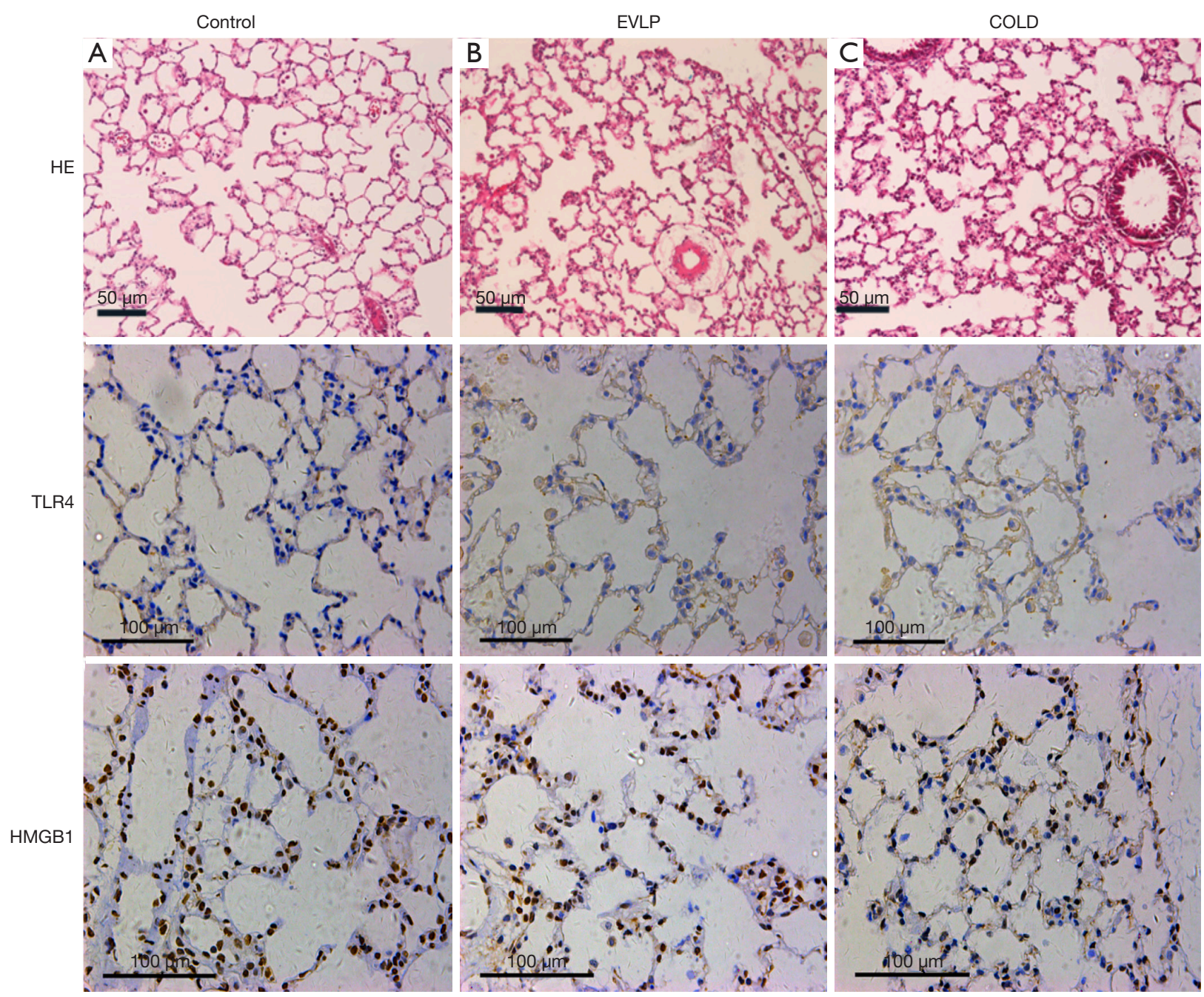

Figure 6 Pathological and histochemical changes of the three groups. Expression of HMGB1 and TLR4 were displayed. EVLP, ex vivo lung perfusion; COLD, conventional cold preservation; TLR4, toll-like receptor 4; HMGB1, high mobility group box 1; HE, hematoxylin-eosin staining.

suitable for transplantation (8). We found that, following 4 hours of normothermic EVLP, the lung functional indexes of the isolated lung were satisfactory. The oxygenation index of the EVLP group remained at nearly $350 \mathrm{mmHg}$ at the endpoint, indicating good lung vitality. Elevated PAP and PVP may result in cardiogenic pulmonary edema and an irreversible loss of alveolocapillary barrier integrity (9). In this study, the PAP and PVP remained at a tolerated low level at the end of 4 hours of EVLP.

Conventional cold preservation technology has a number of limitations, including tissue impairment caused by prolonged cold storage, inhibition of cellular metabolism, difficulty in assessing donor lung viability and function, and a limited opportunity for organ repair (10). In the current study, contrary to the EVLP group (1 hour warm ischemia and 4 hours EVLP), the $\mathrm{PaO}_{2} / \mathrm{FiO}_{2}$ value in the COLD group (1 hour warm ischemia, 3 hours cold ischemia, and 1 hour EVLP) was lower than $300 \mathrm{mmHg}$, implying that the lung physiological function was damaged. Furthermore, we found that the COLD group had a remarkably elevated wet/dry weight ratio, which indicated the extent of pulmonary edema. Similarly, vascular permeability detected by Evans blue dye leakage was significantly severe in the COLD group compared with the EVLP group. Although we gave 1 hour of EVLP to the COLD group, it did not show significant improvements. Arpad Hasenauer 
et al.'s research suggested that EVLP did not improve lung dysfunction and histological damage when applied on cold ischemic lungs, whereas it improved graft function and reduced lung injury when applied on warm ischemic lungs (11). This is consistent with our observations. All the above results showed that early initiation of EVLP rather than cold preservation might protect and repair donor lung.

The protective effect of normothermic EVLP technology on donor lungs may be related to the following factors. First, normothermic EVLP maintains the basic physiological function for lung metabolism with similar complexity and preparation time as COLD group. Second, the high concentration of albumin in our perfusates is beneficial to reduce pulmonary edema. However, there was still some damage due to the prolonged perfusion time. The PAP slightly increased during the 4 hours of perfusion compared to the control group. In this study, we defined an optimum period of EVLP as 4 hours according to the clinical study of the Toronto group (4). With the development of the EVLP technique, an extended (12 hours) EVLP at normothermia may be feasible (5). Last but not least, our fresh perfusate is a kind of low potassium solution which was made of Dextran, electrocyte, and albumin according to the Steen solution formulation (12). The main electrolyte concentrations were as follows: $\mathrm{Na}^{+} 145 \mathrm{mmol} / \mathrm{L} ; \mathrm{K}^{+} 4.5 \mathrm{mmol} / \mathrm{L} ; \mathrm{Ca}^{2+}$ $0.61 \mathrm{mmol} / \mathrm{L} ; \mathrm{Cl}^{-} 113 \mathrm{mmol} / \mathrm{L}$; Osmotic pressure $294 \mathrm{mOsm} / \mathrm{L} ; 50 \mathrm{~g} / \mathrm{mL}$ of Dextran; and $5 \%$ of albumin (5). In addition, we prevented bacteria from entering our perfusate by means of a $0.22-\mu \mathrm{m}$ bacterial filter for the sterilization of Dextran and albumin (13).

HMGB1 is released from multiple cells such as alveolar macrophages, lymphocytes, some epithelial cells, and necrotic cells (14). HMGB1/TLR4 is an important inflammation-related signaling pathway involved in the pathogenesis of ischemia-reperfusion injury $(15,16)$. HMGB1 interacts with its PRRs (RAGE, TLR2, and TLR4) to upregulate expression of pro-inflammatory cytokines (17). HMGB1 levels in human lungs post-EVLP were associated with the development of primary graft dysfunction (PGD) and were accompanied with increasing mortality (18). The extent of PGD should be evaluated in the first hours following clinical lung transplantation (LTx), by measuring biomarker HMGB1 level to assess early inflammatory. On the other hand, LTx is associated with sterile inflammation for release of damage associated with molecular patterns (DAMPs) by injured allograft cells (17). DAMPs target receptors, such as toll-like receptors and NOD-like receptors, activate the nuclear factor kappa B and the inflammasome, release of inflammatory mediators, and increase recruitment of inflammatory cells, which eventually promote graft damage and PGD (17). One of the indicators of DAMPs is a high level of HMGB1 in transplanted warm ischemic lungs, which is consistent with the role of HMGB1 as a direct inducer of lung sterile inflammation (17). Feature study is needed to estimate which gene-set were changed with RNA-seq of EVLP rat lung (19).

In our study, pathological examination confirmed variant lung injury in isolated lungs. Severe damage could be seen in the COLD group. Meanwhile, the expressions of HMGB1 and TLR4 in the EVLP and COLD groups were both higher than in the control group. However, there was no significant difference in TLR4 or HMGB1 between the EVLP and COLD groups. In other words, EVLP had no significant advantage over COLD groups for reducing the expression of inflammatory factors. Previous studies have shown that the role of EVLP is mainly to remove circulating white blood cells, thereby reducing the pool of leukocytes from the donor lungs (20,21). Anti-inflammatory therapies have been established to improve the outcome of lung transplantation. In animal models of EVLP, adenosine agonist was added into the perfusate to reduce lung edema and enhance gas exchange $(22,23)$. Research has also shown that treatment of injured human donor lungs with the anti-inflammatory cytokine IL-10 can improve lung function (24). However, EVLP technology provides a platform for anti-inflammatory treatment, and it is valuable for lung quality maintenance and lung repair (25).

\section{Conclusions}

The EVLP technique is valuable for lung quality maintenance and lung repair during perfusion, and it provides a potential platform for anti-inflammatory treatment. Our study showed that EVLP for DCD rat lungs with our fresh lung perfusates achieved superior protection than conventional cold preservation on physiological function, integrity of barrier function, and pathological changes.

\section{Acknowledgments}

We are grateful to Dr. Yunjing Wang and Avon Yang for helpful discussions and critical reading of our draft manuscript.

Funding: The study was supported by National Key Research and Development Program of China (No. 
2018YFC1313604).

\section{Footnote}

Reporting Checklist: The authors have completed the ARRIVE reporting checklist. Available at https://atm. amegroups.com/article/view/10.21037/atm-22-42/rc

Data Sharing Statement: Available at https://atm.amegroups. com/article/view/10.21037/atm-22-42/dss

Conflicts of Interest: All authors have completed the ICMJE uniform disclosure form (available at https://atm. amegroups.com/article/view/10.21037/atm-22-42/coif). The authors have no conflicts of interest to declare.

Ethical Statement: The authors are accountable for all aspects of the work in ensuring that questions related to the accuracy or integrity of any part of the work are appropriately investigated and resolved. The experiment was approved by the ethics committee of Shanghai Chest Hospital (No. KS2058), in compliance with institutional guidelines for the care and use of animals.

Open Access Statement: This is an Open Access article distributed in accordance with the Creative Commons Attribution-NonCommercial-NoDerivs 4.0 International License (CC BY-NC-ND 4.0), which permits the noncommercial replication and distribution of the article with the strict proviso that no changes or edits are made and the original work is properly cited (including links to both the formal publication through the relevant DOI and the license). See: https://creativecommons.org/licenses/by-nc-nd/4.0/.

\section{References}

1. Punch JD, Hayes DH, LaPorte FB, et al. Organ donation and utilization in the United States, 1996-2005. Am J Transplant 2007;7:1327-38.

2. Zhao J, Liu D, Huang J, et al. The Low Utilization Rate of Donor Lungs in China: A Single-Center Experience. Ann Transplant 2021;26:e931409.

3. Makdisi G, Makdisi T, Jarmi T, et al. Ex vivo lung perfusion review of a revolutionary technology. Ann Transl Med 2017;5:343.

4. Cypel M, Yeung JC, Liu M, et al. Normothermic ex vivo lung perfusion in clinical lung transplantation. $\mathrm{N}$ Engl $\mathrm{J}$ Med 2011;364:1431-40.
5. Cypel M, Yeung JC, Hirayama S, et al. Technique for prolonged normothermic ex vivo lung perfusion. J Heart Lung Transplant 2008;27:1319-25.

6. Cypel M, Rubacha M, Yeung J, et al. Normothermic ex vivo perfusion prevents lung injury compared to extended cold preservation for transplantation. Am J Transplant 2009;9:2262-9.

7. Fernandes LM, Mariani AW, Medeiros IL, et al. Alternative solution for ex vivo lung perfusion, experimental study on donated human lungs non-accepted for transplantation. Acta Cir Bras 2015;30:359-65.

8. Possoz J, Neyrinck A, Van Raemdonck D. Ex vivo lung perfusion prior to transplantation: an overview of current clinical practice worldwide. J Thorac Dis 2019;11:1635-50.

9. Pierre AF, DeCampos KN, Liu M, et al. Rapid reperfusion causes stress failure in ischemic rat lungs. J Thorac Cardiovasc Surg 1998;116:932-42.

10. Jing L, Yao L, Zhao M, et al. Organ preservation: from the past to the future. Acta Pharmacol Sin 2018;39:845-57.

11. Hasenauer A, Bédat B, Parapanov R, et al. Effects of cold or warm ischemia and ex-vivo lung perfusion on the release of damage associated molecular patterns and inflammatory cytokines in experimental lung transplantation. J Heart Lung Transplant 2021;40:905-16.

12. Bassani GA, Lonati C, Brambilla D, et al. Ex Vivo Lung Perfusion in the Rat: Detailed Procedure and Videos. PLoS One 2016;11:e0167898.

13. Inci I, Arni S, Inci D, et al. Impact of topical cooling solution and prediction of pulmonary graft viability from non-heart-beating donors. J Heart Lung Transplant 2008;27:1016-22.

14. Tolle LB, Standiford TJ. Danger-associated molecular patterns (DAMPs) in acute lung injury. J Pathol 2013;229:145-56.

15. Scaffidi P, Misteli T, Bianchi ME. Release of chromatin protein HMGB1 by necrotic cells triggers inflammation. Nature 2002;418:191-5. Erratum in: Nature 2010;467:622.

16. Avlonitis VS, Fisher AJ, Kirby JA, et al. Pulmonary transplantation: the role of brain death in donor lung injury. Transplantation 2003;75:1928-33.

17. Frye CC, Bery AI, Kreisel D, et al. Sterile inflammation in thoracic transplantation. Cell Mol Life Sci 2021;78:581-601.

18. Abraham E, Arcaroli J, Carmody A, et al. HMG-1 as a mediator of acute lung inflammation. J Immunol 2000;165:2950-4.

19. Sharma P, Bansal A, Sharma PC. RNA-seq-based transcriptome profiling reveals differential gene expression 
in the lungs of Sprague-Dawley rats during earlyphase acute hypobaric hypoxia. Mol Genet Genomics 2015;290:2225-40.

20. Wang X, Parapanov R, Debonneville A, et al. Treatment with 3-aminobenzamide during ex vivo lung perfusion of damaged rat lungs reduces graft injury and dysfunction after transplantation. Am J Transplant 2020;20:967-76.

21. Yeung JC, Zamel R, Klement W, et al. Towards donor lung recovery-gene expression changes during ex vivo lung perfusion of human lungs. Am J Transplant 2018;18:1518-26.

22. Mulloy DP, Sharma AK, Fernandez LG, et al. Adenosine A3 receptor activation attenuates lung ischemia-

Cite this article as: Wang W, Qian J, Zhu M, Wang Y, Pan Y. Normothermic ex vivo lung perfusion outperforms conventional cold preservation in a deceased rat lung. Ann Transl Med 2022;10(2):99. doi: 10.21037/atm-22-42 reperfusion injury. Ann Thorac Surg 2013;95:1762-7.

23. Emaminia A, Lapar DJ, Zhao Y, et al. Adenosine $\mathrm{A}_{2} \mathrm{~A}$ agonist improves lung function during ex vivo lung perfusion. Ann Thorac Surg 2011;92:1840-6.

24. Cypel M, Liu M, Rubacha M, et al. Functional repair of human donor lungs by IL-10 gene therapy. Sci Transl Med 2009; 1:4ra9.

25. Tane S, Noda K, Shigemura N. Ex Vivo Lung Perfusion: A Key Tool for Translational Science in the Lungs. Chest 2017;151:1220-8.

(English Language Editor: C. Mullens) 